\title{
The Negative Effects and Control of Blended Learning in University
}

\author{
Shengjian Chen ${ }^{1, a}$,Yun $\mathrm{Lu}^{2, \mathrm{~b}}$ \\ ${ }^{1}$ Institute of Educational Technology, Qujing Normal University Qujing Yunnan,655011, China \\ ${ }^{2}$ Institute of Educational Technology, Qujing Normal University Qujing Yunnan,655011, China \\ aemail:qjsycsj@126.com, bemail:915879686@qq.com
}

Keywords: Blended Learning; Negative Effects; University

\begin{abstract}
Blended learning is becoming more and more popular in recent years for it blended the advantages of traditional teaching and online teaching. But there are some negative effects in blended learning, such as the definition is not clear, students' cognitive load increased, teachers are difficult to grasp the model of blended learning, and the teaching process is more complex. The main idea of this paper is to put forward the corresponding control measures to solve the problems that mentioned above, and to improve the quality of blended learning.
\end{abstract}

\section{Introduction}

Blended learning is the formation of a profound reflection of the traditional classroom face-toface teaching and distance online learning styles. It has been widely used in higher education and primary and secondary education and become a hot research filed of educational technology. Many educational researchers and teachers admired on the blended learning because that blended learning is the most effective way of learning for blended learning combining the advantages of classroom face-to-face teaching and distance online leaning [1] [2]. However, when we applaud the highlights and advantages of blended learning we also should strong concern about on its negative effects. In this paper, author discuss negative effects and control method of blended learning in college based on the author eight years experiences.

\section{The Negative Effect and Control on Conception}

\section{The Negative Effect}

Blended learning has so many definitions. Some scholar thinks that blended learning is face-to face learning, some believes blended learning is the mixture of the theory of cognitivism, behaviorism and constructivism, some stresses that blended learning is the combination of different teaching models, some scholars holds the opinion that blended learning is the mixture of face-toface learning, free study and online study. Curtis Bonk's research: When I visit South Korea, Tai Wan, China, Britain, Canada and some other countries, many scholars have expressed their confusion on the concept of blended learning [3].It can be seen from these definitions that scholars are confused to the concept of blended learning. This will be influence the process of dissemination and promotion, and audience and practitioners understand the concept of fuzzy, so they have psychological rejection or offensive.

\section{Control}

To avoid the negative effect which caused by the unclear and widely of the connotation of blended leaning, it is necessary for us to find the essence of blended learning, only do this, can we avoid the negative effects. Blended learning derived from the corporate training. The entrepreneurs find: "There are some disadvantages on single face-to-face learning and online learning, only the combination of the two can complement each other's disadvantages". So they called for face learning and E-learning merging training model as blended learning. From the development and process of blended learning we find the essence of blended learning is that, in the process of study, students integrate face-to-face learning and online learning to achieve the advantages of the each 
other.

\section{The Negative Effect and Control for Teachers}

\section{The Negative Effect}

The negative effect of "blended learning" for teachers is overwork, hard to choose right learning mode and difficult to control the proportion of face-to-face learning and online learning. Zhan Zehui and Li Xiaohua thinks that teachers designs and carry out to blended learning, but they find it's effectiveness they do not willing to continue [4]."Blended learning require teachers to pay a lot of time on familiar the design process and methods of blended learning, the operation of a variety of delivery methods and the characteristics and use of medias to design a variety of teaching and learning strategies which based on curriculum objectives. Try their best to collect, collate, make learning resources" [5].we also cone across the same problem in recent years, it is hard to control the proportion of face-to-face learning and online learning on blended learning.

\section{Control}

To avoid the negative effect. At first, we should increase the training of teachers. We should enhance teachers' acceptance of IT in technical training, decrease teachers' sense of mystery and fear of new technology and equipment. In the process of training, we should not only pay attention to the conception of blended learning, but also show every kind of blended learning cases and examples, told that they may encounter various problems and solutions.

Secondly, we should change the incentives of the school. Schools should increase the input for the courage of teachers to try blended learning teaching model through the education reform project and to increase the unit class fees way to motivate teachers.

Thirdly, teachers may prepare classes and teaching together to reduce the workload. For public courses, with the support of online teaching platform of blended learning, on the same course, teachers can be divided into chapters to prepare the resources and design learning activities, then to discuss the formation of network courses to share. and the future reuse, greatly reducing the burden on teachers. In the process of curriculum implementation and also can be divided into sections of online tutoring.

Lastly, we should solve the problem of how to hybrid in blended learning. There are many successful blended learning model we can learn from, of which webquest is a very worth learning mode. To the problem of how to control the proportion of face-to-face learning and online learning is according to the teaching content. The best proportion is face-to-face learning time: online learning time $=1: 3$ [6]. For the content which is difficult for self-learning, the best way for teacher is through face-to-face classroom instruction and face-to-face classroom discussion to complete. For those content is not difficult to memory or operate, teachers can design or providing Internet links resources through a web course, so students can complete the course online or online discussion.

\section{The Negative Effect and Control for Students}

\section{The Negative Effect}

The negative effect of the blended learning for students is mainly in the cognitive load, learning styles, and working conditions. One misunderstanding teachers often make in the implementation of blended learning is that teachers pay much attention on the network platform and they design a lot of activities to allow students to learn more. But the result of doing so makes the students' cognitive load increased blended learning counterproductive. In addition, the different backgrounds of the students have their own learning styles, some students are accustomed to reading a textbook, they like outlined and annotated in the textbooks. If we give students a lot of learning content and ask them for digital learning, it will influence the learning effect. Once again, Because function of the network platform is not good cause the negative effects of the navigation lost, not easy operation. Finally, in the process of blended learning implementation, because the high expenses increase the cost of getting resources, it will also affect students' learning effect.

\section{Control}


Individual differences on the audience tells us that when we use media or different delivery methods in blended learning, we should based on the learner's learning style or learning attitude, this fact emphasized on the education motive excitation and teach students in accordance of their aptitude [7]. Motivation can link the goal of blended learning and learner's expectation, and then spread blended learning to students. So when teacher design a blended learning course, it's necessary to analyze student by questionnaires to have a better understanding about students' learning style and the convenience of Internet. On this basis, we should determine what learning resources to provide the network of digital resources, which learning resources to provide the paper. The support platform of online teaching should obey the design of the content of network while supporting the rich network of interactive teaching principles.

\section{The Negative Effect and Control on Learning Resources}

\section{The Negative Effect}

The negative effect of the learning resources to students is the design of resources lack of interactive and selective. Some teachers often use electric resources to communicate with students (such as e-books) as the teaching resource of blended learning, this kind of learning also lack of interaction. In order to have a better usage of Internet learning resources, and provide rich Internet resources to students to look for the information they need. In fact, too much learning resources is way of waste of time and it spend too much energy.

\section{Control}

In today's society, there is more and more open educational resources and types are abundant, so teachers should use these qualities resources for them srudents. The teachers in the information age also have the responsibility to guide learners, teach them to search for information, and use of open educational resources, to accumulate more capital for them to become lifelong learners. But at the same time teachers should carefully select high-quality teaching resources for students, doing like this not only help students broaden their vision but also help students find the right direction, avoid wasting of time.

\section{The Negative Effect and Control on Evaluation}

\section{The Negative Effect}

Assessment abuout blended learning is diversified. It contains classroom performance, examinations, and practical in traditional classroom teaching, and online learning, online discussion, online quizzes, and online assessment in online learning. This make students' learning effectiveness evaluation becomes difficult to grasp in blended learning, such as electronic job plagiarism problem and the proportion of evaluation. Online learning provide students a wealth of learning resources, convenient interaction and sharing of resources, at the same time online learning give birth to the “network research" family, "network copy” family, and "passive” family [8].

\section{Control}

To avoid the negative effect. The first, we should strengthen the education of integrity and awareness of intellectual property rights, we should let them to realize that plagiarism is an offense.

The second, when a teacher designs homework to students, they try to designs the homework which can't directly search it's answer by Internet. This will avoid plagiarism to some extent. For example, when teaching image processing technology, the teacher can require students to use their own digital photos as a material, learning acquisition and processing technology of sound material, require students to record their own voice and then use it.

The third, to students plagiarism, we can use some technical means, such as anti-plagiarism detection to prevent copying. Such as online jobs which based on Moodle network, we can use the platform to provide "anti-copying plug-ins" to stop plagiarism.

The fourth, make a scientific proportion of the elements of blended learning evaluation. Through the practice of several blended learning courses in Educational Technology and Technology Integration into Curriculum, found that the best proportion is the performance in face-to-face 
learning $10 \%+$ the performance in online learning(include online scamming and post) $10 \%+$ homework $20 \%$ +final examination $40 \%$ [9].

\section{Conclusion}

Theory research and practice tells us that blended learning combines the advantages of traditional teaching and online teaching, it can achieve the two complement each other. Because blended learning involve some complex teaching factors, and it difficult to control the effectiveness of learning variable, so there are a number of teaching negative effect. However, if we have a better understanding of the essence of blended learning, learn from successful experience from others, and try our best to blended learning and sum up experiences from practice we can control the negative effect in blended learning.

\section{Acknowledgements}

This work get grant from key course project foundation (ZDKC2011004) and teaching reform project (Syjx2011005) of Qujing Normal University .We would like to thank them.

\section{References}

[1] Zehui Zhan, Xiaohua Li. Blended Learning: Definition, Strategy,the Present Situation and Trend of Development. China Audio-Visual Education, vol.12 ,pp.1,2009.

[2]The new development of educational technology theory. From Blending Learning (on). Educational technology research 2004 (3): 1

[3] Zehui Zhan, Xiaohua Li. Blended Learning: Definition, Strategy,the Present Situation and Trend of Development. China Audio-Visual Education, vol.12 ,pp.1,2009.

[4] Zehui Zhan, Xiaohua Li. Blended Learning: Definition, Strategy,the Present Situation and Trend of Development. China Audio-Visual Education, vol.12 ,pp.1,2009..

[5] Yunwen Li.The Action Research of Applying Blended Learning to Modern Educational Technology Curriculum in Traditional Normal University , Capital Normal University,2005,pp.81

[6] Shengjian Chen,Weiqi Ma. Study on Blended Learning Ccourse Design and Teaching EffectivenessJ. Education Technology Research, vol.2 ,pp.8-11,2008.

[7] Yunwen Li. The Action Research of Applying Blended Learning to Modern Educational Technology Curriculum in Traditional Normal University, Capital Normal University,2005,pp.29.

[8] Edger.Dale.Audio Visual Methods In Teaching.YN:Dryden Press,1946,pp.3-5.

[9] Shengjian Chen.Study on Satisfaction with Moodle in Blended Learning.Education Technology Research,vol.12,pp.32-34,2009. 